\title{
Efeito da sobrealimentação com fontes de proteína de diferentes degradabilidades sobre a ovulação em ovelhas Santa Inês ${ }^{1}$
}

\author{
Gabriela de Abreu Saunders², Nadja Gomes Alves², Juan Ramón Olalquiaga Pérez², \\ José Camisão de Souza ${ }^{2}$, Joel Augusto Muniz ${ }^{3}$, Antônio José Neto ${ }^{2}$ \\ ${ }^{1}$ Apoio financeiro: Fundação de Amparo à Pesquisa do Estado de Minas Gerais - FAPEMIG e Conselho Nacional de Desenvolvimento \\ Científico e Tecnológico - CNPq. \\ 2 Departamento de Zootecnia da Universidade Federal de Lavras. \\ ${ }^{3}$ Departamento de Estatística da Universidade Federal de Lavras.
}

RESUMO - Este estudo foi realizado com o objetivo de avaliar a concentração plasmática de N-ureico, o número de ovulações e o diâmetro do folículo ovulatório de ovelhas da raça Santa Inês submetidas a sobrealimentação com fontes de proteína de diferentes degradabilidades ruminais. Quarenta e quatro ovelhas com o estro sincronizado receberam dietas isoproteicas, formuladas com farelo de soja $(n=24)$ ou com glúten de milho e farelo de algodão ( $\mathrm{n}=20)$ durante 28 dias antes da ovulação. Os animais foram distribuídos em delineamento de blocos, com os blocos formados por três faixas de escore de condição corporal. O ganho de peso vivo e de escore de condição corporal, o peso vivo e o escore de condição corporal no 28 o dia do experimento, a concentração plasmática de N-ureico, o número de ovulações e o diâmetro do folículo ovulatório não diferiram entre as ovelhas submetidas à sobrealimentação com farelo de soja ou com glúten de milho e farelo de algodão. As ovelhas que receberam sobrealimentação com farelo de soja apresentaram maior concentração plasmática de N-ureico nos dias 7 e 14 e menor no dia 28 em comparação às que receberam sobrealimentação com glúten de milho e farelo de algodão (interação dieta vs dia). O fornecimento de uma dieta com menor teor de proteína degradável no rúmen não reduz concentração plasmática de $\mathrm{N}$-ureico nem altera o número de ovulações e o diâmetro do folículo ovulatório.

Palavras-chave: concentração plasmática de N-ureico, farelo de soja, folículos ovarianos, glúten de milho

\section{Effect of flushing with sources of protein with different degratability on ovulation in Santa Inês ewes}

\begin{abstract}
This study aimed at evaluating plasma concentration of urea nitrogen, the number of ovulations and the diameter of ovulatory follicle of Santa Ines ewes submitted to flushing with sources of protein with different ruminal degradabilities. Forty-four estrus-synchronized ewes were fed isoprotein diets composed of soybean meal $(\mathrm{n}=24)$ or corn gluten meal and cottonseed meal $(\mathrm{n}=20)$ for 28 days before ovulation. Animals were distributed in a block design in which the blocks were formed by three score ranges of body condition score. Body weight and body condition score gains, body weight and body condition score on the $28^{\text {th }}$ experimental day, urea nitrogen plasma concentration, number of ovulations and diameter of the ovulatory follicle did not differ among ewes submitted to flushing with soybean meal or with corn gluten and cottonseed meal. Ewes under soybean meal flushing showed higher urea nitrogen plasma concentration on days seven and 14 and lower concentration on the $28^{\text {th }}$ day when compared to those fed corn gluten and cottonseed meal (day vs. diet interaction). The supply of one diet with lower content of ruminal degradable protein does not reduce urea nitrogen plasma concentration neither alters the number of ovulations and diameter of ovulatory follicle.
\end{abstract}

Key Words: corn gluten meal, ovarian follicles, plasma urea nitrogen, soybean meal

\section{Introdução}

O aumento do nível nutricional ou sobrealimentação refere-se à prática de fornecer às ovelhas uma dieta densa em nutrientes durante duas a três semanas antes do início da estação reprodutiva visando aumentar a taxa de ovulação (Gordon, 1997) e é geralmente acompanhado por aumento do peso vivo e do escore de condição corporal (ECC, Rassu et al., 2004).

Os tratamentos nutricionais podem influenciar a taxa de ovulação por alterarem a metabolização hepática de hormônios esteroides. Segundo Smith \& Stewart (1990), maior tamanho hepático e a maior concentração das enzimas hepáticas observados nos animais com alta ingestão de 
alimentos foram relacionados à maior metabolização dos hormônios esteroides e, consequentemente, à diminuição do feedback negativo destes hormônios na liberação de gonadotrofinas, hormônio folículo estimulante (FSH) e hormônio luteinizante(LH). Além disso, o aumento na ingestão de energia eleva a concentração sanguínea de insulina e do fator de crescimento semelhante à insulina (IGF-I), os quais agem sobre os folículos em associação ao FSH, estimulando o desenvolvimento folicular (Fortune et al., 2004).

Embora os efeitos da sobrealimentação com dietas ricas em energia sejam bem documentados (Rhind et al., 1989; Vinõles et al., 2008), as informações relativas à sobrealimentação com alimentos proteicos são escassas. Molle et al. (1997) observaram maior número de ovulações em ovelhas da raça Sarda sob sobrealimentação com 270 $\mathrm{g}$ de farelo de soja/dia a partir de 14 dias antes até dois dias após a monta, do que em ovelhas não suplementadas (1,8 vs 1,3 corpos lúteos, respectivamente). Branca etal.(2000), estudando ovelhas da raça Sarda que receberam dietas isoprotéicas e isoenergéticas, uma com farelo de soja e outra com glúten de milho, que diferiram na quantidade de proteína degradável no rúmen (PDR), por 14 dias antes até dois dias após a inseminação artificial, não observaram diferença no número de ovulações ( 1,89 vs 2,28 , respectivamente).

O fornecimento de dietas ricas em proteína, principalmente com elevada quantidade de PDR, pode gerar um excesso de amônia no rúmen, que será detoxificada no fígado, pelo ciclo da ureia, com gasto de energia (Santos \& Greco, 2007). Assim, o excesso de proteína ou de PDR na dieta pode elevar a concentração de N-ureico no sangue (Elrod et al., 1993). A relação entre concentração de amônia e ou de N-ureico no sangue e a taxa de ovulação em ovelhas foi pouco estudado. Apenas dois trabalhos foram encontrados na literatura consultada e em ambos a taxa de ovulação não foi relacionada à concentração plasmática de ureia (Fahey et al., 2001) ou de N-ureico (Bishonga et al., 1996). Em vacas, Garcia-Bojalil et al. (1998b) relataram que menor atividade ovariana nos primeiros 50 a 57 dias pósparto esteve associada ao consumo de uma dieta com $15,7 \%$ de PDR, em comparação à outra com $11,1 \%$ de PDR. A menor atividade ovariana foi relacionada à maior concentração de N-ureico e a menor concentração de insulina no plasma (Garcia-Bojalil et al., 1998a).

Visek (1984) propôs que a alta concentração de amônia no sangue pode inibir as células betapancreáticas, ocasionando diminuição do estímulo da glicose sobre a liberação de insulina, o que reduziria a concentração de insulina na circulação sanguínea. O menor teor de proteína degradável no rúmen na dieta poderia reduzir a concentração de N-ureico no plasma, contribuindo para o aumento da concentração sanguínea de insulina, a qual, juntamente com o IGF-I, seriam favoráveis ao desenvolvimento folicular e ao número de ovulações.

Esta pesquisa foi realizada com o objetivo de avaliar a concentração plasmática de $\mathrm{N}$-ureico, o número de ovulações e o diâmetro do folículo ovulatório de ovelhas da raça Santa Inês submetidas à sobrealimentação com fontes de proteína degradável no rúmen.

\section{Material e Métodos}

O experimento foi realizado no Setor de Ovinocultura do Departamento de Zootecnia da UFLA, no período de setembro a dezembro de 2007. Foram utilizadas 44 ovelhas da raça Santa Inês, multíparas, não gestantes, em bom estado sanitário e clínico geral, com peso médio de $51,33 \pm 0,15 \mathrm{~kg}$ e ECC entre 2,25 e 3,25. A avaliação do ECC foi feita considerando uma escala de 0 a 5 , sendo $0=$ emaciada e 5 = muito gorda (Gordon, 1997). As ovelhas foram distribuídas em um delineamento de blocos, sendo estes formados por três faixas de ECC $(2,25$ a 2,50; 2,75 e 3,00 a 3,25).

As ovelhas foram submetidas à sobrealimentação com uma dieta contendo farelo de soja $(n=24)$ ou outra contendo glúten de milho e farelo de algodão $(\mathrm{n}=20)$ por 28 dias antes da data prevista para a ovulação. As dietas foram calculadas conforme o AFRC (1993), considerando o peso vivo médio das ovelhas de $55 \mathrm{~kg}$ e consumo diário de matéria seca (MS) de 1,5 $\mathrm{kg}$ (Tabela 1). Para estimativa dos teores de proteína degradável no rúmen e proteína não-degradável no rúmen na proteína bruta (PB) e da energia metabolizável (EM), foi utilizado o Small Ruminant Nutrition System (SRNS, 2008).

As ovelhas foram mantidas em baias coletivas, respeitando-se o limite máximo de 12 ovelhas por baia. As dietas foram fornecidas na forma de mistura completa, duas vezes ao dia. O consumo das dietas foi ajustado em porcentagem de peso vivo para que o consumo de MS fosse semelhante entre as ovelhas que receberam estas dietas. Diariamente, as sobras de cada baia foram retiradas e pesadas, para determinação de consumo do grupo e estimativa do consumo médio individual. Amostras das sobras e do alimento fornecido foram coletadas, acondicionadas em sacos plásticos e armazenadas a $-20^{\circ} \mathrm{C}$, para posterior análise bromatológica dos alimentos e das amostras compostas por semana. As análises de MS, PB, EE, FDNc e cinzas foram realizadas de acordo com Silva \& Queiroz (2002), no Laboratório de Ciência Animal do Departamento de Zootecnia da UFLA. Os carboidratos não-fibrosos foi determinado pela equação: $\mathrm{CNF}=100$ $(\mathrm{PB}+\mathrm{EE}+\mathrm{FDNc}+$ Cinzas $)$. 
Tabela 1 - Composição das dietas experimentais, formuladas com duas fontes de proteína degradável no rúmen

\begin{tabular}{lcc}
\hline & & Dieta \\
\cline { 2 - 3 } Ingrediente & Farelo de soja & Glúten de milho + farelo de algodão \\
\hline Silagem de milho (\% MS) & 72,14 & 73,27 \\
Farelo de soja (\% MS) & 13,98 & 7,45 \\
Glúten de milho (\% MS) & \\
Farelo de algodão (\% MS) & 9,25 \\
Polpa cítrica (\% MS) & 4,62 & 4,96 \\
Sal mineral (\% MS) & & 9,55 \\
Nutrientes & 41,31 & 4,77 \\
Matéria seca (\% MN) & 90,89 & 12,04 \\
Matéria orgânica (\% MS) & 79,30 & 41,22 \\
Proteína bruta (\% MS) & 20,70 & 91,21 \\
Proté́na degradável no rúmen (\% PB) & 43,81 & 12,25 \\
Proteína não-degradável no rúmen (\% PB) & 3,11 & 65,60 \\
Fibra em detergente neutro corrigida para cinzas (\% MS) & 34,40 \\
Extrato etéreo (\% MS) & 31,93 & 40,83 \\
Carboidratos não-fibrosos (\% MS) & 9,11 & 3,90 \\
Cinzas (\% MS) & 3,96 & 8,79 \\
Energia metabolizável (Mcal/dia) & & 3,93 \\
\hline
\end{tabular}

FDNc: fibra em detergente neutro corrigida para cinzas.

${ }^{1}$ Níveis de garantia por kg do produto: $\mathrm{P}-80 \mathrm{~g} ; \mathrm{Mg}-18 \mathrm{~g} ; \mathrm{Na}-150 \mathrm{~g} ; \mathrm{S}-15 \mathrm{~g}$; Ca - $125 \mathrm{mg}$; Co - $65 \mathrm{mg} ; \mathrm{I}-95 \mathrm{mg} ; \mathrm{Mn}-1.500 \mathrm{mg} ; \mathrm{Se}-30 \mathrm{mg} ; \mathrm{Zn}-350 \mathrm{mg} ; \mathrm{F}-800 \mathrm{mg}$; vit. A - 30.000 UI; vit. D - 3.000 UI; vit. E - 60 UI.

As ovelhas foram pesadas e o ECC foi avaliado semanalmente, até o fim do experimento. Amostras de sangue de todas as ovelhas foram coletadas por punção da veia jugular, em tubos de vidro de coleta à vácuo com anticoagulante EDTA, para dosagem de ureia no plasma. As amostras foram coletadas nos dias sete, 14, 21 e 28 a partir do fornecimento das dietas. As amostras foram coletadas aproximadamente 4 horas após a alimentação, acondicionadas em caixa de isopor com gelo e centrifugadas a 1582 x g para obtenção de plasma, que foi identificado e armazenado a $-20^{\circ} \mathrm{C}$ para posterior análise. As análises de ureia foram realizadas por método colorimétrico enzimático, utilizando kit comercial (Ureia $500^{\circledR}$, Doles Reagentes e Equipamentos para Laboratórios Ltda, Belo Horizonte, MG). Posteriormente os dados de ureia no plasma foram transformados para $\mathrm{N}$-ureico, multiplicando-se o valor de ureia encontrado na análise por 0,4666 , equivalente a porcentagem do nitrogênio presente na molécula de ureia.

O protocolo de sincronização de estros foi iniciado no 17 o dia após o início do fornecimento das dietas. Foram utilizadas esponjas intravaginais impregnadas com $60 \mathrm{mg}$ de acetato de medroxiprogesterona (MAP $60^{\circledR}$, Tecnopec, Brasil) por 11 dias e aplicação de 300 UI de eCG (Novormon ${ }^{\circledR}$, Syntex S.A.) e $50 \mathrm{mg}$ de cloprostenol (Prolise ${ }^{\circledR}$, ARSA S. R. L.), via intramuscular, no $9^{\circ}$ dia após a inserção da esponja intravaginal. A partir de 12 horas após a retirada das esponjas a manifestação de estros foi monitorada duas vezes ao dia (das 8 às 9 h e das 17 às 18 h), com auxílio de rufiões.

As ovelhas em estro tiveram o número de ovulações determinado por ultrassonografia transretal, utilizando um aparelho marca CHISSON 500 com um transdutor linear de $5 \mathrm{MHz}$, o qual foi acoplado a uma extensão rígida ( $3 \mathrm{~cm}$ de diâmetro e $16 \mathrm{~cm}$ de comprimento) que permitiu sua manipulação no reto. A ovulação foi determinada pelo desaparecimento dos folículos dominantes presentes na superfície dos ovários.

O efeito da sobrealimentação com farelo soja ou com glúten de milho e farelo de algodão sobre o ganho de peso e o escore de condição corporal e a concentração plasmática de N-ureico, o peso e o ECC no 28 o dia após o início da sobrealimentação, o número de ovulações e o diâmetro do folículo ovulatório, foram submetidos à análise de variância, com comparação das médias pelo teste $\mathrm{F}$, adotando-se o nível de $5 \%$ de probabilidade (SAS, 1999). Como não houve interação entre as dietas e o bloco, considerado erro experimental, esta interação não foi considerada no modelo estatístico (Banzatto \& Kronka, 2006). O modelo estatístico utilizado foi:

$$
\mathrm{Y}_{\mathrm{ij}}=\mu+\mathrm{A}_{\mathrm{i}}+\mathrm{B}_{\mathrm{j}}+\varepsilon_{\mathrm{ijk}}
$$

em que: $\mu=$ constante inerente a cada observação; $A_{i}=$ efeito da fonte de proteína $(i=1,2) ; B_{j}=$ efeito da faixa de escore $(j=1,2$ e 3$) ; \varepsilon_{i j k}=$ erro experimental aleatório, independente com distribuição normal de média zero e variância $\sigma^{2}(\mathrm{k}=1,2,3 \mathrm{e} 4)$.

A concentração de $\mathrm{N}$-ureico no plasma foi analisada segundo um esquema em parcela subdividida no tempo, considerando duas dietas (sobrealimentação com farelo de soja ou com glúten de milho e farelo de algodão) e as semanas de coleta de sangue, com comparação de médias 
pelo teste Tukey, adotando-se o nível de 5\% de probabilidade (SAS, 1999):

$$
\text { Yijk }=\mu+T_{i}+\varepsilon_{i j}+D_{k}+T_{i k}+\varepsilon_{i j k}
$$

em que: $\mu=$ constante inerente a cada observação; $\mathrm{T}_{\mathrm{i}}=$ efeito da dieta $(\mathrm{i}=1,2)$ ou $(\mathrm{i}=1,2,3$ e 4$) ; \varepsilon_{\mathrm{ij}}=$ erro experimental associado à parcela, considerado independente e identicamente distribuído de uma normal de média zero e variância $\sigma^{2} ; \mathrm{D}_{\mathrm{k}}=$ efeito do tempo $(\mathrm{k}=1,2,3$ e 4); $\mathrm{TD}_{\mathrm{ik}}=$ interação entre a dieta e o tempo; $\varepsilon_{\mathrm{ijk}}=$ erro experimental associado à subparcela, considerado independente e identicamente distribuído de uma normal de média zero e variância $\sigma^{2}$.

Correlações simples de Pearson foram estimadas entre todas as variáveis quantitativas (SAS, 1999).

\section{Resultados e Discussão}

A alimentação das ovelhas foi realizada em baias coletivas, portanto, os dados de consumo (Tabela 2) são estimativas do consumo médio individual, pois não foram analisados estatisticamente. As ovelhas submetidas à sobrealimentação com farelo de soja ou com glúten de milho e farelo de algodão apresentaram o mesmo consumo médio individual de PB. As ovelhas consumiram o correspondente a 1,6 vez a exigência de EM de mantença e 1,86 vez a exigência de proteína de mantença.

Alguns autores observaram que dietas contendo glúten de milho reduziram a ingestão de MS por bovinos e ovinos (Costa, 2001; Salvador, 2007). No entanto, o glúten de milho na quantidade utilizada neste experimento não reduziu o consumo de MS. A proporção desse ingrediente na dieta (7,45\% da MS) foi próxima ao nível máximo consumido por cordeiras Santa Inês (7,91\%) em experimento conduzido por Salvador (2007).

Santos et al. (1998), ao analisar três artigos (Holter et al., 1992; Polan et al., 1991; Wohlt et al., 1991), em que o farelo

Tabela 2 - Estimativa do consumo médio individual de matéria seca, de matéria orgânica e de nutrientes

\begin{tabular}{lcc}
\hline & \multicolumn{2}{c}{ Dieta } \\
\cline { 2 - 3 } Consumo & $\begin{array}{r}\text { Farelo } \\
\text { de soja }\end{array}$ & $\begin{array}{c}\text { Glúten de milho + } \\
\text { farelo de algodão }\end{array}$ \\
\hline Matéria seca (\% do PV) & 2,96 & 2,93 \\
Matéria seca (kg/dia) & 1,638 & 1,613 \\
Matéria orgânica (kg/dia) & 1,489 & 1,471 \\
Proteína bruta (kg/dia) & 0,198 & 0,198 \\
Carboidratos não-fibrosos (kg/dia) & 0,524 & 0,571 \\
Extrato etéreo (kg/dia) & 0,51 & 0,47 \\
Fibra em detergente neutro & 0,716 & 0,656 \\
corrigida para cinzas (kg/dia) & & 0,142 \\
Cinzas (kg/dia) & 0,149 & 0 \\
\hline
\end{tabular}

de soja foi totalmente substituído pelo glúten de milho em dietas à base de silagem de milho para vacas leiteiras, observaram menor ingestão de MS. Em nenhum dos trabalhos analisados a causa da redução na ingestão de MS foi relatada. No entanto, a redução no consumo pode ter como causa a baixa palatabilidade do glúten de milho (Teixeira, 1997).

Os ganhos de peso vivo (PV) e de escore de condição corporal, o peso vivo e o escore de condição corporal ao final do período experimental não diferiram $(\mathrm{P}>0,05)$ entre as ovelhas que receberam a sobrealimentação com farelo de soja ou com glúten de milho e farelo de algodão (Tabela 3 ). A avaliação das duas dietas no SRNS (2008) indicou que os animais ingeriram quantidades semelhantes de EM (3,9 Mcal/dia), justificando a ausência de diferença no ganho de PV e de ECC e, portanto, no PV e no ECC ao final do experimento.

Branca et al. (2000) também não observaram diferença no ganho de PV e de ECC de ovelhas suplementadas com dois concentrados isoproteicos, contendo farelo de soja ou glúten de milho, durante os 14 dias antes até dois dias após a inseminação artificial. O ganho diário de PV das ovelhas (52 e $29 \mathrm{~g} /$ dia, respectivamente) foi menor do que o observado no presente estudo $(116 \pm 0,02$ e $109 \pm 0,02 \mathrm{~g} / \mathrm{dia}$ nas ovelhas submetidas à sobrealimentação com farelo de soja ou glúten de milho e farelo de algodão, respectivamente). A diferença no ganho de PV das ovelhas entre os dois estudos se deve à maior duração do fornecimento das dietas neste experimento ( 28 dias) em relação aos 16 dias de sobrealimentação no estudo de Branca et al. (2000), e ao estado produtivo dos animais, pois, os autores trabalharam com ovelhas lactantes, enquanto neste estudo as ovelhas estavam secas. No entanto, Molle et al. (1997), estudando ovelhas em lactação, observaram perda de $12 \mathrm{~g}$ de peso corporal por dia nos animais suplementados com $270 \mathrm{~g}$ de farelo de soja durante 14 dias antes da cobertura.

A concentração plasmática de $\mathrm{N}$-ureico não diferiu $(\mathrm{P}>0,05)$ entre as ovelhas que receberam sobrealimentação com farelo de soja ou com glúten de milho e farelo de

Tabela 3 - Ganho de peso vivo e de escore de condição corporal (ECC) durante o período experimental e peso vivo e escore de condição corporal no $28^{\circ}$ dia do experimento

\begin{tabular}{lrr}
\hline \multirow{2}{*}{ Item } & \multicolumn{2}{c}{ Dieta } \\
\cline { 2 - 3 } & $\begin{array}{c}\text { Farelo de } \\
\text { soja }(\mathrm{n}=24)\end{array}$ & $\begin{array}{c}\text { Glúten de milho + farelo } \\
\text { de algodão }(\mathrm{n}=20)\end{array}$ \\
\hline Ganho de peso vivo (kg) & $3,14 \pm 0,55$ & $2,94 \pm 0,61$ \\
Ganho de ECC & $0,04 \pm 0,05$ & $0,10 \pm 0,06$ \\
Peso vivo final (kg) & $54,46 \pm 1,31$ & $53,36 \pm 1,44$ \\
ECC final & $2,78 \pm 0,05$ & $2,85 \pm 0,05$ \\
\hline
\end{tabular}

$\mathrm{n}=$ número de animais. 
algodão $(17,25 \pm 0,60$ vs $16,23 \pm 0,66 \mathrm{mg} / \mathrm{dL}$, respectivamente). Esses valores foram maiores que os relatados por McEvoy et al. (1997) em dois experimentos realizados com ovelhas adultas Border Leicester $\times$ Stottish Blackface, não lactantes, alimentadas com dietas para atender as exigências de mantença (5,5 e 6,7 mg/dL). Berardinelli et al. (2001), em estudo com ovelhas Western White-Faced, não-lactantes, mantidas com dietas que atenderam a exigência de proteína de mantença, observaram concentração de N-ureico no plasma de 13,1 mg/dL. A concentração plasmática de $\mathrm{N}$-ureico neste estudo sugere que houve excesso de proteína na dieta consumida pelas ovelhas, o que gerou excesso de amônia e subsequente conversão a ureia.

Ao analisar a concentração plasmática de N-ureico durante os 28 dias antes da ovulação observou-se interação dieta vs dia $(\mathrm{P}<0,0001)$. Nos animais submetidos à sobrealimentação com farelo de soja, a concentração de $\mathrm{N}$-ureico no $14^{\circ}$ dia foi maior $(\mathrm{P}<0,05)$ que a observada nos dias 7 e 28 e igual $(\mathrm{P}>0,05)$ à observada no dia 21 . Os animais que receberam sobrealimentação com glúten de milho e farelo de algodão apresentaram maior concentração de N-ureico nos dias 21 e 28 que nos dias 7 e 14. Essa concentração de N-ureico nos dias 7 e 14 nas ovelhas submetidas à sobrealimentação com farelo de soja foi maior $(\mathrm{P}<0,05)$ que naquelas que receberam glúten de milho e farelo de algodão. Ao contrário, no $28^{0}$ dia a concentração de $\mathrm{N}$-ureico foi maior nas ovelhas que consumiram glúten de milho e farelo de algodão (Tabela 4).

As concentrações de ureia e de $\mathrm{N}$-ureico no plasma estão diretamente associadas à ingestão de PB (Claypool et al., 1980) e de nitrogênio (Moscardini et al., 1998, Cannas et al., 1998). Durante períodos de alta disponibilidade ruminal de nitrogênio, como ocorre com o consumo de dietas ricas em PDR, a produção de amônia no rúmen pode ser maior que a utilização pelas bactérias ruminais, gerando um excesso de amônia que será convertido à ureia, no fígado, com gasto de energia. Por outro lado, o fornecimento de PNDR disponibiliza aminoácidos que serão absorvidos no intestino delgado e deaminados no fígado, sendo a amônia detoxificada pelo ciclo da ureia. Assim, tanto o excesso de PDR quanto o de

Tabela 4 - Concentração plasmática de N-ureico nos dias 7, 14, 21 e 28 do experimento

\begin{tabular}{lcc}
\hline & \multicolumn{2}{c}{ N-ureico $(\mathrm{mg} / \mathrm{dL})$} \\
\cline { 2 - 3 } Dia & Farelo de soja & Glúten de milho + farelo de soja \\
\hline 7 & $15,51 \pm 0,86 \mathrm{Ba}$ & $10,26 \pm 0,94 \mathrm{Bb}$ \\
14 & $20,83 \pm 0,86 \mathrm{Aa}$ & $12,62 \pm 0,94 \mathrm{Bb}$ \\
21 & $16,95 \pm 0,86 \mathrm{Ab}$ & $19,77 \pm 0,94 \mathrm{Aa}$ \\
28 & $16,56 \pm 0,86 \mathrm{BCb}$ & $22,49 \pm 0,94 \mathrm{Aa}$ \\
\hline
\end{tabular}

$\mathrm{a}, \mathrm{b}$ - entre dietas $(\mathrm{P}<0,01)$ e $\mathrm{A}, \mathrm{B}$ entre dias de coleta em uma mesma dieta diferem $(\mathrm{P}<0,05)$ pelo teste $\mathrm{F}$.
PNDR elevam a concentração de N-ureico no sangue (Elrod et al., 1993) e este metabólito pode ser um bom indicador da proteína não utilizada pelo animal (Moore \& Varga, 1996, citados por Lucci et al., 2006).

A substituição de farelo de soja por glúten de milho e farelo de algodão não foi efetiva em reduzir a concentração plasmática de $\mathrm{N}$-ureico a partir do $21^{\mathrm{O}}$ dia do experimento, ocasionando inclusive aumento $(\mathrm{P}<0,05)$ desta concentração no 28 o dia (Tabela 4). A explicação para estas observações não é clara, mas poderia estar relacionada ao menor valor biológico do perfil de aminoácidos absorvidos e ao maior catabolismo endógeno de aminoácidos em animais que recebem dietas contendo glúten de milho (Mabjeesh et al., 1998; Swanson et al., 2000). O glúten de milho é um alimento rico em metionina e pobre em lisina $(5,2$ e $3,7 \%$ dos aminoácidos essenciais) e tem 45,2\% de aminoácidos essenciais na $\mathrm{PB}$. O farelo de algodão é uma fonte com teor intermediário de PNDR, pobre em metionina e lisina (3,7 e 9,7 $\%$ dos aminoácidos essenciais) e tem $42,6 \%$ de aminoácidos essenciais na PB. Estes alimentos são considerados fontes proteicas de pior qualidade se comparados à proteína microbiana (Santos \& Greco, 2007). Reynolds (2006) relataram que os aminoácidos absorvidos pelas vísceras drenadas pelo sistema porta (trato gastrointestinal, pâncreas, baço e tecido adiposo associado) podem ser utilizados na síntese de proteínas ou oxidados, sendo que os aminoácidos essenciais são preferencialmente utilizados na síntese proteica, enquanto os não essenciais são preferencialmente oxidados. Os autores relataram ainda que a captação de aminoácidos pelo fígado é proporcional à sua concentração no sangue, especialmente com relação aos aminoácidos não-essenciais, o que poderia aumentar o catabolismo de aminoácidos e a produção de ureia. Desta forma, fica clara a importância de se maximizar a síntese de proteína microbiana no rúmen, pois isto representa um uso eficiente da PDR, menor perda de amônia ruminal, menor excreção de ureia e maior fluxo de aminoácidos essenciais para o intestino (Santos \& Greco, 2007).

$\mathrm{O}$ número de ovulações e o diâmetro do folículo ovulatório não diferiram $(\mathrm{P}>0,05)$ entre as ovelhas submetidas à sobrealimentação com farelo de soja ou glúten de milho e farelo de algodão (Tabela 5).

Tabela 5 - Número de ovulações e diâmetro do folículo ovulatório

\begin{tabular}{lcc}
\hline \multirow{2}{*}{ Item } & \multicolumn{2}{c}{ Dieta } \\
\cline { 2 - 3 } & $\begin{array}{c}\text { Farelo de } \\
\text { soja }\end{array}$ & $\begin{array}{c}\text { Glúten de milho + } \\
\text { farelo de algodão }\end{array}$ \\
\hline Número de ovulações & $2,25 \pm 0,16$ & $2,24 \pm 0,18$ \\
Folículo ovulatório $(\mathrm{mm})$ & $6,61 \pm 0,17$ & $6,72 \pm 0,19$ \\
\hline
\end{tabular}


Não houve correlação entre o número de ovulações e o peso vivo $(\mathrm{r}=0,09, \mathrm{P}>0,05)$ ou o $\mathrm{ECC}(\mathrm{r}=0,17, \mathrm{P}>0,05)$ no $28^{\circ}$ dia do experimento. Assim como não houve correlação entre o número de ovulações e o ganho de peso vivo $(\mathrm{r}=0,24, \mathrm{P}>0,05)$ ou o ganho de $\mathrm{ECC}(\mathrm{r}=0,24, \mathrm{P}>0,05)$ antes da ovulação.

As ovelhas iniciaram o experimento com ECC de 2,74 e ganharam peso e ECC ao longo dos 28 dias de fornecimento das dietas. Durante a semana da ovulação, as ovelhas que receberam sobrealimentação com farelo de soja ou com glúten de milho e farelo de algodão apresentaram ECC de $2,75 \pm 0,05$ ou $2,85 \pm 0,05$, respectivamente. Segundo Gunn et al. (1991), a condição corporal mínima para ovelhas lanadas de origem escocesa manifestarem sua capacidade reprodutiva é de 2,5. Assim, provavelmente, este pode ter sido o motivo da ausência de diferença no número de ovulações e da ausência de correlação entre o número de ovulações e o ECC, o peso vivo, o ganho de ECC e de peso vivo.

Da mesma forma, Branca et al. (2000), em pesquisa com ovelhas da raça Sarda que receberam suplementos isoproteicos (120g de PB/dia) e isoenergéticos, um com farelo de soja e outro com glúten de milho, que diferiram na quantidade de proteína não degradável no rúmen (46 e $85 \mathrm{~g}$ de PNDR/dia), por 14 dias antes até dois dias após a inseminação artificial, não observaram diferença no número de ovulações ( 1,89 vs 2,28, respectivamente) e no escore de condição corporal. A ausência de diferença no número de ovulações foi atribuída ao fornecimento de um volumoso rico em proteína degradável no rúmen, que aumentou a quantidade de proteína degradável no rúmen na dieta total consumida. Além disso, as ovelhas já iniciaram o experimento com ECC de 2,57, acima do limiar de 2,5 estabelecido por Gunn et al. (1991). No presente estudo, as ovelhas consumiram como volumoso a silagem de milho, que também é rica em proteína degradável no rúmen e nitrogênio nãoproteico.

Silva et al. (2010) observaram número de ovulações de 1,5 e 1,7 folículos em ovelhas da raça Santa Inês, com estro sincronizado com prostaglandina F2 $\alpha$ ou com uma associação de progestágeno e eCG, respectivamente. Neste estudo as ovelhas apresentaram número médio de ovulações de 2,24 folículos, superior à média observada em ovelhas da mesma raça, e sugeriram que a sobrealimentação foi efetiva em aumentar o número de ovulações.

Não houve correlação entre o número de ovulações e a concentração de $\mathrm{N}$-ureico no plasma $(\mathrm{r}=-0,08, \mathrm{P}>0,05)$. A ausência de correlação pode estar relacionada à sobrealimentação, que aumenta o fluxo sanguíneo portahepático e a metabolização de hormônios esteroides e reduz o efeito de feedback negativo dos hormônios esteroides sobre a secreção de FSH e LH (Smith \& Stewart, 1990). Existe ainda a possibilidade de a elevada concentração de N-ureico não ser tão prejudicial ao controle hormonal da ovulação quanto é ao oócito (Sinclair et al., 2000) e ao início do desenvolvimento embrionário (Gardner \& Lane, 1993; Hammon et al., 2000; Alves, 2005; Rhoads et al., 2006; Alves et al., 2010).

A concentração plasmática de N-ureico nas ovelhas que receberam sobrealimentação com farelo de soja ou com glúten de milho e farelo de algodão permaneceu abaixo de $19 \mathrm{mg} / \mathrm{dL}$, considerada por alguns autores como prejudicial à reprodução em vacas (Butler et al., 1996; Butler et al., 2005). Branca (2000) relataram que a concentração de N-ureico prejudicial ao desempenho reprodutivo de ovelhas da raça Sarda foi de $26,13 \mathrm{mg} / \mathrm{dL}$ e, portanto, superior ao observado neste estudo.

A alta concentração de amônia no sangue pode inibir as células betapancreáticas, diminuindo o estímulo da glicose sobre a liberação de insulina e reduzindo a concentração sanguínea deste hormônio (Visek, 1984). A insulina é o fator primário da produção de estradiol em bovinos (Butler, 2005). Segundo Butler (2003), a habilidade dos folículos de produzirem estradiol suficiente para desencadear a onda pré-ovulatória de hormônio luteinizante e a ovulação parece depender da disponibilidade de insulina e de IGF-1 circulantes. O IGF-I é um fator mitogênico que, juntamente com a insulina, estimula a proliferação de células da granulosa e o crescimento de pequenos folículos (Butler, 2005). Assim, baixas concentrações de insulina e de IGF-I poderiam diminuir o diâmetro do folículo ovulatório, a secreção de estradiol e o número de ovulações.

Garcia-Bojalil et al. (1998b) relatou maior diâmetro do folículo dominante de vacas alimentadas com dietas contendo $11,1 \%$ de PDR na MS, comparadas àquelas que receberam dieta com $15,7 \%$ de proteína degradável na MS, o que foi relacionado à menor concentração plasmática de insulina nesses animais, em comparação aos que receberam 11,1\% de proteína degradável na dieta (Garcia Bojalil et al., 1998a). Ao contrário, neste estudo, o fornecimento de dietas com diferentes proporções de PDR não influenciou ( $\mathrm{P}>0,05)$ o diâmetro do folículo ovulatório $(6,6$ e 6,7 mm nas ovelhas submetidas à sobrealimentação com farelo de soja ou com glúten de milho e farelo de algodão, respectivamente). O diâmetro do folículo ovulatório, neste estudo, foi similar ao relatado por Cavalcanti (2008) em ovelhas da raça Santa Inês $(6,4 \mathrm{~mm})$.

Como a concentração plasmática de $\mathrm{N}$-ureico, o número de ovulações e o diâmetro do folículo ovulatório, neste estudo, não diferiram entre as ovelhas que receberam fontes de proteína de diferentes degradabilidades ruminais, 
pode-se supor que provavelmente não ocorreu diferença na concentração sanguínea de insulina e de IGF-I. Além disso, em vista do número de ovulações observado, é provável que esses hormônios tenham tido suas concentrações aumentadas, em decorrência da alta ingestão de energia metabolizável, relativa às exigências nutricionais.

\section{Conclusões}

O fornecimento de uma dieta com fontes de proteína de menor degradabilidade ruminal não reduz a concentração plasmática de $\mathrm{N}$-ureico nem influencia o número de ovulações e o diâmetro do folículo ovulatório em ovelhas da raça Santa Inês.

\section{Agradecimentos}

À Universidade Federal de Lavras, pela oportunidade de condução deste estudo. À Fundação de Amparo à Pesquisa do Estado de Minas Gerais (FAPEMIG), pelo financiamento do projeto de pesquisa. Ao Conselho Nacional de Desenvolvimento Científico e Tecnológico (CNPq), pela concessão da bolsa de estudos. À empresa Tecnopec, pela doação dos hormônios utilizados na sincronização de estros. Aos colegas que ajudaram na condução do experimento.

\section{Referências}

AGRICULTURAL AND FOOD RESEARCH COUNCIL - AFRC. Energy and protein requirements of ruminants. Wallingford: CAB International, 1993. 159p.

ALVES, F.R.; MARTINS, C.M.; BRAGA, F.A. et al. Efeitos do fornecimento de dietas contendo nitrogênio não-protéico a fêmeas bovinas superovuladas sem prévia adaptação, durante curto tempo e em diferentes fases do ciclo estral. Revista Brasileira de Zootecnia, v.39, p.1928-1936, 2010.

ALVES, N.G. Efeito de ureia na dieta sobre as características reprodutivas e concentração de progesterona e metabólitos em cabras da raça Alpina. 2005. 166f. Tese (Doutorado em Zootecnia) - Universidade Federal de Viçosa, Viçosa, MG.

BANZATTO, D.A.; KRONKA, S.N. Experimentação àgrícola. 4.ed. Jaboticabal: FUNEP, 2006. 237p.

BERARDINELLI, J.G.; WENIG, J.; BURFENING, P.J. et al. Effect of excess degradable intake protein on early embryonic development, ovarian steroid and blood urea nitrogen on days $2,3,4$, and 5 of the estrus cycle in mature ewes. Journal of Animal Science, v.79, n.1, p.193-199, 2001.

BISHONGA, C.; ROBINSON, J.J.; McEVOY, T.G. et al. Excess dietary urea intake in ewes and its effect on ovulation rate and embryo development. Japanese Journal of Veterinary Research, v.44, n.3, p.139-151, 1996.

BRANCA, A.; MOLLE, G.; SITZIA, M. et al. Short-term dietary effects on reproductive wastage after induced ovulation and artificial insemination in primiparous lactating Sarda ewes. Animal Reproduction Science, v.58, n.1-2, p.59-71, 2000 .
BUTLER, W.R.; CALAMAN, J.J.; BEAM, S.W. Plasma and milk urea nitrogen in relation to pregnancy rate in lactating dairy cattle. Journal of Animal Science, v.74, n.4, p.858-865, 1996.

BUTLER, W.R. Energy balance relationships with follicular development, ovulation and fertility in postpartum dairy cows. Livestock Production Science, v.83, n.2-3, p.211-218, 2003.

BUTLER, W.R. Inhibition of ovulation in the postpartum cow and the lactating sow. Livestock Production Science, v.98, n.1-2, p.5-12, 2005.

CANNAS, A.; PES, A.; MANCUSO, R. et al. Effect of dietary energy and protein concentration on the concentration of milk urea nitrogen in dairy ewes. Journal of Dairy Science, v.81, n.2, p.499-508, 1998.

CAVALCANTI, A.S. Avaliação do uso de GnRH em protocolos curtos de indução e sincronização do estro e da ovulação em ovelhas. 2008. 111f. Dissertação (Mestrado em Clínica e Reprodução Animal) - Universidade Federal Fluminense, Niterói.

CLAYPOOL, D.W.; PANGBORN, M.C.; ADAMS, P.H. Effect of dietary protein on high-producing dairy cows in early lactation. Journal of Dairy Science, v.63, n.4, p.833-837, 1980.

COSTA, R.M. Avaliação de suplementos com proteína degradável e de escape ruminal para recria de bovinos. 2001. 47f. Dissertação (Mestrado em Zootecnia) - Universidade Estadual Paulista/FCAV, Jaboticabal.

ELROD, C.C.; VAN AMBURGH, M.; BUTLER, W.R. Alterations of $\mathrm{pH}$ in response to increased dietary protein in cattle are unique to the uterus. Journal of Animal Science, v.71, n.3, p.702-706, 1993.

FAHEY, J.; BOLAND, M.P.; O'CALLAGHAN, D. The effects of dietary urea on embryo development in superovulated donor ewes and on early embryo survival and development in recipient ewes. Journal of Animal Science, v.72, n.2, p.395-400, 2001.

FORTUNE, J.E.; RIVERA, G.M.; YANG, M.Y. Follicular development: the role of follicular microenvironment in selection of the dominant follicle. Animal Reproduction Science, v.82-83, n.1, p.109-126, 2004.

GARCIA-BOJALIL, C.M.; STAPLES, C.R.; RISCO, C.A. et al. Protein degradability and calcium salts of long-chain fatty acids in the diets of lactating dairy cows: productive responses. Journal of Dairy Science, v.81, n.5, p.1374-1384, 1998a

GARCIA-BOJALIL, C.M.; STAPLES, C.R.; RISCO, C.A. et al. Protein degradability and calcium salts of long-chain fatty acids in the diets of lactating dairy cows: reproductive responses. Journal of Dairy Science, v.81, n.5, p.1385-1395, 1998b.

GARDNER, D.K.; LANE, M. Amino acids and ammonium regulate mouse embryo development in culture. Biology of Reproduction, v.48, n.2, p.377-385, 1993.

GORDON, I. Controlled reproduction in sheep \& goats. New York: CAB International, 1997. v.2. 450p.

GUNN, R.G.; MAXWELL, T.J.; SIM, D.A. et al. The effect of level of nutrition prior to mating on the reproductive performance of ewes of two welsh breeds in different levels of body condition. Animal Production, v.52, n.1-2, p.157-163, 1991.

HAMMON, D.S.; WANG, S.; HOLYOAK, G.R. Effects of ammonia during different stages of culture on development of in vitro produced bovine embryos. Animal Reproduction Science, v.59, n.1-2, p.23-30, 2000.

HOLTER, J.B.; HAYES, H.H. Response of Holstein cows to corn gluten meal used to increase undegradable protein in early or later lactation. Journal of Dairy Science, v.75, p.1495-1506, 1992.

LUCCI, C.S.; VALVASORI, E.; PEIXOTO JR., K. et al. Concentrações de nitrogênio na dieta, no sangue e no leite de vacas lactantes no período pós-parto. Revista Brasileira de Zootecnia, v.35, n.1, p.258-263, 2006

MABJEESH, S.J.; ARIELI, A. Heat-treated whole cottonseed versus maize gluten meal as a rumen undegradable protein supplement for lactating dairy cows. Livestock Production Science, v.55, n.3, p.249-259, 1998. 
McEVOY, T.G.; ROBINSON, J.J.; AITKEN, R.P. et al. Dietary excesses of urea influence the viability and metabolism of preimplantation sheep embryos and may affect fetal growth among survivors. Animal Reproduction Science, v.47, n.1-2, p.71-90, 1997.

MOLLE, G.; LANDAU, S.; BRANCA, A. et al. Flushing with soybean meal can improve reproductive performances in lactating Sarda ewes on a mature pasture. Small Ruminant Research, v.24, n.2, p.157-165, 1997.

MOSCARDINI, S.; WRIGHT, T.C.; LUIMES, P.H. et al. Effects of rumen-undegradable protein and feed intake on purine derivate and urea nitrogen:comparison with predictions from the Cornell Net Carbohydrate and protein system. Journal of Dairy Science, v.81, n.10, p.2421-2429, 1998.

POLAN, C.E.; CUMMINS, K.A.; SNIFFEN, C.J. et al. Responses of dairy cows to supplemental rumen-protected forms of methionine and lysine. Journal of Dairy Science, v.74, p.2997-3013, 1991.

RASSU, S.P.G.; ENNE, G.; LIGIOS S. et al. Nutrition and Reproduction. In: PULINA, G.; BENCINI, R. (Eds.) Dairy sheep nutrition. Cambridge: CAB Internacional, 2004. p.217-222.

REYNOLDS, C.K. Splanchinc amino acid metabolism in ruminants. In: SEJRSEN, K.; HVELPLUND, T.; NIELSEN, M.O. (Eds.) Ruminant physiology: digestion, metabolism and impact of nutrition on gene expression, immunology and stress. Wageningen: Wageningen Academic Publishers, 2006. p.225-244.

RHIND, S.M.; McKELVEY, W.A.C.; McMILLEN, S.R. et al. Effect of restricted food intake before and/or after mating, on the reproductive performance of Greyface ewes. Animal Production, v.48, n.2, p.149-155, 1989.

RHOADS, M.L.; RHOADS, R.P.; GILBERT, R.O. et al. Detrimental effects of high plasma urea nitrogen levels on viability of embryos from lactating dairy cows. Animal Reproduction Science, v.91, n.1-2, p.1-10, 2006.

SALVADOR, F.M. Proteína degradável no rúmen e proteína metabolizável em ovinos em crescimento. 2007. 147f. Tese (Doutorado em Nutrição de Ruminantes) - Universidade Federal de Lavras, Lavras.

SANTOS, F.A.P.; SANTOS, J.E.P.; THEURER, C.D. et al. Effects of rumen undegradable protein on dairy cow performance: A 12- year literature review. Journal of Dairy Science, v.81, n. 12, p. 3182-3213, 1998.

SANTOS, F.A.P.; GRECO, L.F. Digestão pós-ruminal de proteínas e exigências de aminoácidos para ruminantes. In: RENNÓ, F.P.;
SILVA, L.F.P. (Eds.) In: SIMPÓSIO INTERNACIONAL AVANÇOS EM TÉCNICAS DE PESQUISA EM NUTRIÇÃO DE RUMINANTES, 2007, Pirassununga. Anais... Pirassununga: USP - Faculdade de Medicina Veterinária e Zootecnia, 2007. p. $90-120$

SILVA, B.D.M.; SARTORI, R.; SILVA, T.A.S.N. et al. Sincronização de estro com prostaglandina $F 2 \alpha$ versus progestágeno associado à gonadotrofina coriônica equina $(\mathrm{eCG})$ em ovelhas Santa Inês no Distrito Federal. Ciência Animal Brasileira, v.11, p.417-424, 2010 .

SILVA, D.J.; QUEIROZ, A.C. Análise de alimentos (métodos químicos e biológicos). Viçosa, MG: Editora UFV, 2002. 235p.

SINCLAIR, K.D.; KURAN, M.; GEBBIE, F.E. et al. Nitrogen metabolism and fertility in cattle: II. Development of oocytes recovered from heifers offered diets differing in their rate of nitrogen release in the rumen. Journal of Animal Science, v.78, n.10, p.2670-2680, 2000

SMALL RUMINAT NUTRITION SYSTEM - SRNS. Versão 1.8.4. College Station: Texas University, 2008. 8p.

SMITH, A.J.; STEWART, R.D. Effects of nutrition on the ovulation rate of ewes. In: OLDHAM, C.M.; MARTIN, G.B.; PURVIS, I.W. (Eds.) Reproductive physiology of Merino sheep concepts and consequences. Perth: School of Agriculture (Animal Science), The University of Western Australia, 1990. p.85-101.

SWANSON, K.C.; CATON, J.S.; REDMER, D.A. et al. Influence of undegraded intake protein on intake, digestion, serum hormones and metabolites, and nitrogen balance in sheep. Small Ruminat Research, v.35, n.3, p.225-233, 2000.

STATISTICAL ANALYSES SYSTEM INSTITUTE - SAS. SAS/ STAT user's guide: statistics. 4.ed. Cary, 1999. v.2, 943p.

TEIXEIRA, J.C. Nutrição de ruminantes. Lavras: FAEPE, 1997. $239 \mathrm{p}$

VIÑOLES, C.; MEIKLE, A.; MARTIN, G.B. Short-term nutritional treatments grazing legumes or feeding concentrates increase prolificacy in Corriedale Ewes. Animal Reproduction Science, v.113, n.1-4, p.82-92, 2008.

VISEK W.J. Ammonia: its effects on biological systems, metabolic hormones and reproduction. Journal of Dairy Science, v.67, n.2, p.481-498, 1984.

WOHLT, J.E.; CHMIEL, S.L.; KAJAC, P.K. et al. Dry matter intake, milk yield and composition, and nitrogen use in Holstein cows fed soybean, fish, or corn gluten meals. Journal of Dairy Science, v.74, p.1609-1622, 1991. 